\title{
Efeito da sinvastatina na sepse abdominal de ratos diabéticos
}

\section{Effect of the simvastatin in abdominal sepsis of diabetic rats}

Irami Araúuo-Filho, tCBC-RN"; Daniel TÔrres Jácome²; Amália Cínthia Meneses Rêgo3; ítalo Medeiros Azevedo4; ERyvaldo Sócrates Tabosa Egito5; Aldo Cunha Medeiros, TCBC-RN 6

\section{R E S U M O}

\begin{abstract}
Objetivo: Analisar se o pré-tratamento com sinvastatina em modelo experimental de sepse abdominal é benéfico em ratos diabéticos. Métodos: Cinquenta e seis ratos Wistar foram aleatoriamente distribuídos em: grupo não diabético (n-28) e grupo diabetes induzido por estreptozotocina $(n=28)$. Sepse abdominal por ligadura e punção do ceco foi induzida em 14 ratos diabéticos e em 14 não diabéticos. Os demais 28 animais foram alocados em grupo sham. Os grupos de ratos com sepse e os sham (cada com sete animais) foram tratados com microemulsão oral de simvastatina (20 mg kg-1 day-1) e solução salina 0,9\%, respectivamente. Sangue periférico foi usado para dosagem de TNF $\alpha$, IL-1 $\beta$, IL-6, proteína $C$ reativa, procalcitonina, contagem de leucócitos e neutrófilos em todos os animais. A análise estatística foi realizada pela ANOVA e teste de Tukey, com $p<0,05$. Resultados: A sinvastatina reduziu a mortalidade nos ratos diabéticos. Os valores séricos de TNF- $\alpha$, IL-1 $\beta$, IL-6, proteína C reativa, procalcitonina, leucócitos e neutrófilos mostraram-se mais baixos nos ratos diabéticos e não diabéticos com sepse, tratados com sinvastatina, do que nos tratados com solução salina. Conclusão: A sinvastatina teve efeito antiinflamatório, que pode ter resultado em proteção contra a sepse em ratos diabéticos.
\end{abstract}

Descritores: Sepse. Sinvastatina. Diabetes. Estreptozotocina. Ratos.

\section{INTRODUÇÃO}

I: nfecção e sepse são as causas mais frequentes de morbidade e mortalidade no trauma e no pós-opertório de pacientes diabéticos. A sepse está associada com anormalidades no fluxo sanguíneo sistêmico e microcirculatório, devido a distúrbios da coagulação, diminuição na capacidade de deformabilidade das hemácias, aumento na permeabilidade microvascular, alteração na resistência vascular, lesão de células endoteliais e diminuição da oferta de oxigênio às células ${ }^{1-3}$. Esses distúrbios microcirculatórios podem levar a uma hipoperfusão e disfunção tecidual, com conseqüentes alterações cardiovasculares ${ }^{4}$. A resposta inflamatória inclui alguns mecanismos fisiológicos de defesa, com o objetivo de limitar e reparar lesões teciduais. A liberação de citocinas próinflamatórias, incluindo o fator de necrose tumoral-alfa (TNF-

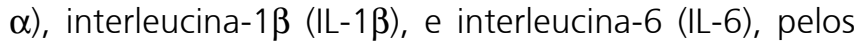
macrófagos e outras células, desempenha um papel central na orquestração desses mecanismos. Eles são considerados de valor prognóstico, pois podem ser o prenúncio da gravidade e da resolução da sepse, uma vez que têm um papel chave na sua patogênese ${ }^{5}$. Nos hepatócitos, a res- posta das citocinas estimula a síntese de proteínas da fase aguda da inflamação, como a proteína $C$ reativa $(P C R)$, cuja concentração aumenta entre a quarta e a sexta horas após o início da infecção e dobra de valor a cada oito horas $^{6}$. A procalcitonina (PCT) é um importante pro-hormônio marcador da sepse, que é o precursor da calcitonina. Ela tem respondido a estratégias de tratamento da sepse e representa um marcador promissor para o monitoramento dos efeitos do tratamento?

Pacientes diabéticos são de alto risco para desenvolver infecção urinária, infecção respiratória, de pele e de tecidos moles, quando comparados com pacientes de grupos controles ${ }^{8}$. Tem-se defendido a hipótese de que o aumento da susceptibilidade dos diabéticos à infecção é devido à diminuição dos seus mecanismos de defesa, incluindo o número e a função dos polimorfonucleares e dos linfócitos, bem como diminuição da resposta das citocinas ${ }^{9,10}$.

As estatinas inibem a HMG-CoA redutase, e têm sido estudadas extensivamente em relação à aterosclerose, uma doença inflamatória do endotélio vascular, cuja patogênese tem muitas semelhanças com a patogênese da sepse ${ }^{11}$. Embora os efeitos das estatinas tenham sido inicialmente atribuídos apenas à redução dos níveis de

Estudo realizado no Departamento de Cirurgia e Programa de Pós-graduação em Ciências da Saúde, Universidade Federal do Rio Grande do Norte (UFRN), Natal, Brasil.

1. Professor Adjunto do Departamento de Cirurgia da Universidade Federal do Rio Grande do Norte - UFRN, Natal, Brasil. 2. Estudante de Medicina do Programa de Iniciação Científica da Universidade Federal do Rio Grande do Norte - UFRN, Natal, Brasil. 3. Aluna do Doutorado do Programa de Pós-Graduação em Ciências da Saúde da Universidade Federal do Rio Grande do Norte - UFRN, Natal, Brasil. 4. Estatístico do Departamento de Cirurgia da Universidade Federal do Rio Grande do Norte - UFRN, Natal, Brasil. 5. Professor Associado do Departamento de Farmácia da Universidade Federal do Rio Grande do Norte - UFRN, Natal, Brasil. 6. Professor Titular do Departamento de Cirurgia da Universidade Federal do Rio Grande do Norte - UFRN, Natal, Brasil. 
lipídeos, muitos outros benefícios passaram a ser considerados e estudados ${ }^{12}$. As estatinas exercem múltiplos efeitos em várias células, através de um número considerável de mecanismos. Esses denominados efeitos pleiotrópicos têm sido descritos como antiinflamatórios, pois modificam as interações entre o endotélio e os leucócitos, alterando as respostas dessas células ${ }^{13,14}$. Adicionalmente, as estatinas modulam a sinalização das células inflamatórias, repercutindo na redução da liberação de citocinas e de proteínas da fase aguda da sepse $\mathrm{e}^{13,15}$, além de exercerem importantes efeitos antioxidantes por vários mecanismos ${ }^{16}$.

Este trabalho teve o objetivo de tentar responder a questão se a sinvastatina interfere na evolução da sepse abdominal em ratos diabéticos. Foram avaliados: mortalidade, níveis séricos de citocinas pró-inflamatórias, PCT, PCR e leucometria em modelo experimental de sepse abdominal e diabetes.

\section{MÉTODOS}

Foram utilizados 56 ratos Wistar com quatro meses de idade, pesando $265 \pm 31$ g, fornecidos pelo Biotério do Centro de Ciências da Saúde da Universidade Federal do Rio Grande do Norte, Brasil. O protocolo experimental foi aprovado pela Comissão Institucional de Pesquisa com Animais e a pesquisa foi realizada de acordo com as regras recomendadas pelo Colégio Brasileiro de Experimentação Animal.

Os animais foram aleatoriamente alocados em um grupo não diabético $(n=28)$, e em outro grupo cujo diabetes foi induzido por estreptozotocina $(n=28)$. A glicemia de todos os ratos foi normal antes do experimento. Cada animal do grupo diabetes recebeu por via intraperitonial injeção de estreptozotocina $(65$ mg/kg; Sigma Chemical, St. Louis, MO) diluída em $0.1 \mathrm{~mol} / \mathrm{l}$ de citrato. Após 48 horas, foi colhido sangue periférico da veia caudal para dosage de glicose. Animais com glicemia acima de 200 mg/dL foram considerados diabéticos. A glicemia em jejum foi medida através do Accu-Chek Active System (Roche Diagnostics, Germany). Todos eles foram mantidos em sala com ar condicionado, ciclo de claro-escuro de 12 horas e acesso livre a água e alimento (Labina-Purina) durante os experimentos. Para prevenir morte súbita, tal como ocorre na cetoacidose diabética, todos os ratos que apresentaram glicemia acima de $400 \mathrm{mg} / \mathrm{dL}$ receberam injeção subcutânea de insulina de longa duração (0.5 U duas vezes ao dia por uma semana), de acordo com o lível da glicemia. Ratos não diabéticos foram tratados com o mesmo volume e dose de citrato, via subcutânea. A sepse abdominal foi induzida em 14 ratos diabéticos e em 14 não diabéticos e os demais ratos foram alocados no grupo similação (sham) (Figura 1).

\section{Indução da sepse}

Os animais foram mantidos em jejum por $12 \mathrm{hr}$ antes do procedimento cirúrgico e anestesiados com injeção intramuscular de 0,1 mL/100g de peso, de uma solução preparada com 1,0 mL of cetamina $(50 \mathrm{mg} / \mathrm{mL})$ e 1,0
$\mathrm{mL}$ de xilazina $(20 \mathrm{mg} / \mathrm{mL})$. Os ratos foram mantidos em respiração espontânea durante os procedimentos. Após a depilação, a pele do abdomen foi desinfectada com álcool $70 \%$ e a intervenção cirúrgica foi realizada em condições assépticas. Uma laparotomia de $3 \mathrm{~cm}$ foi realizada na linha mediana, o ceco foi exposto e feita sua ligadura com fio de seda 2-0, a um centímetro da válvula ileocecal para evitar obstrução. Quatro punções foram realizadas com agulha $25 \times 0.7 \mathrm{~mm}$, o ceco foi suavemente apertado para permitir a saída de fezes e foi recolocado na cavidade abdominal. A incisão abdominal foi suturada com nylon 4-0. Nos animais do grupo sham foi feita apenas a laparotomia $(3 \mathrm{~cm})$ e suave manipulação do ceco com pinça atraumática. Nas primeiras 24 horas do pós-operatório a dor foi controlada com tramadol ( $20 \mu \mathrm{g} / \mathrm{g}$ de peso) e a hidratação foi feita com solução salina $0.9 \%$ (0.05 mL/g de peso) via subcutânea, imediatamente após a indução da sepse e em seguida a cada oito horas.

\section{Tratamento medicamentoso}

Uma semana após a indução do diabetes, foi feito o tratamento com sinvastatina ou com solução salina $0,9 \%$, conforme está descrito na figura 1 . Os ratos tratados com sinvastatina receberam o fármaco via oral na dose de $20 \mathrm{mg} / \mathrm{Kg}$ na forma de microemulsão por gavagem, 18 horas e três horas antes da ligadura e punção do ceco (LPC).

\section{Dosagens laboratoriais}

Todos os animais foram observados por 24 horas. Os ratos sobreviventes foram anestesiados com cetamina intramuscular $(50 \mathrm{mg} / \mathrm{kg}$ ). Amostras de sangue foram coletadas por punção cardíaca para dosagem de fator de necrose tumoral-alfa (TNF $\alpha$ ), interleucina-1 $\beta$ (IL-1 $\beta$ ) e interleucina-6 (IL-6), usando a técnica ELISA com kits da PeproTech, Rocky Hill, NJ, USA, de acordo com os protocolos recomendados pelo fabricante. A fluorescência foi medida através do leitor de microplacas Bio-Tec Instruments EL 808, usando o software KC4-V3.0. A sensibilidade de detecção foi de $20 \mathrm{pg} / \mathrm{ml}$ para citocinas. A concentração sérica de procalcitonina (PCT) foi determinada em duplicata através de ensaio imunoluminométrico (Brahms, PCTLIA, Berlin, Germany). A menor concentração de PCT detectável por esta técnica foi $0,08 \mathrm{ng} / \mathrm{mL}$ e o valor de referência estabelecido pelo método foi $<0,5 \mathrm{ng} / \mathrm{mL}$. A proteina $C$ reativa $(P C R)$ foi dosada por imunoturbidimetria, usando o equipamento Orion Diagnostica (Orion Diagnostica Oy, Finlândia), e o valor de referência estabelecido pelo método foi de 0 a $3 \mathrm{mg} / \mathrm{L}$.

\section{Contagem de leucócitos}

Amostras de sangue total foram usadas para contagem de leucócitos e percentual de neutrófilos, usando-se contador automático de células (Abbott Cell-Dyn 3500RCD 3500 5L, USA).

\section{Análise estatística}

Os dados foram apresentados como média土DP. Valores de $p<0,05$ foram considerados significantes. Análi- 
se de variância (ANOVA) acompanhado do teste de Tukey foram usados para comparar os grupos. Todos os testes estatísticos foram realizados usando-se software comercialmente disponível (Statistica Versão 6.1; Stat Soft, Tulsa, $\mathrm{OK})$.

\section{Delineamento experimental}

Pode ser observado na figura 1.

\section{RESULTADOS}

\section{Mortalidade}

No grupo de ratos diabéticos com sepse, tratados com sinvastatina (Se/S), nenhuma morte foi observada durante o período de observação. Entre os animais sépticos diabéticos, tratados com solução salina (Se/SL), ocorreram duas mortes. Um deles morreu após oito horas da indução da sepse e um outro após 15 horas. Nenhuma morte ocorreu nos ratos do grupo sham. Por outro lado, um rato do grupo Se/SL não diabético morreu minutos antes de completar 24 horas da CLP.

\section{Não diabéticos}

Nos ratos do grupo Se/SL os leucócitos totais e o percentual de neutrófilos mostraram-se mais elevados do que nos demais grupos, sinalizando que o uso da sinvastatina em ratos não diabéticos reduziu significativamente a reação leucocitária $(p<0,05)$. Nos ratos do grupo sham nenhuma diferença foi observada na comparação da leucometria dos animais tratados (Sh/S) e não tratados com sinvastatina (sh/SL). Esses dados estão resumidos na tabela 1.

Analisando os dados da tabela 1, observamos que os valores de TNF- $\alpha$, IL- $1 \beta$ e IL- 6 são mais baixos nos ratos sépticos tratados com sinvastatina (Se/S), com- parados com os ratos tratados com solução salina (Se/ $\mathrm{SL})$ e a diferença é significante $(\mathrm{p}<0,05)$. Comparando os valores das citocinas nos animais sépticos com os do grupo sham, as diferenças são igualmente significantes $(p<0.05)$.

\section{Animais diabéticos}

Nos animais diabéticos com sepse observamos que o tratamento com sinvastatina reduziu de modo significante a contagem de leucócitos e o percentual de neutrófilos quando comparados com os ratos tratados com solução salina $(p<0,05)$. Esses dados estão resumidos na tabela 2. O tratamento com sinvastatina não alterou a leucometria no grupo sham dos ratos diabéticos. Comparando os dados das tabelas 1 e 2, observa-se que a leucometria e o percentual de neutrófilos são significantemente mais elevados nos animais diabéticos do que nos não diabéticos $(p<0,05)$.

Os dados da tabela 2 mostram que nos ratos diabéticos sépticos tratados com sinvastatina (Se/S) os valores das citocinas são significtivamente mais baixos do que nos ratos tratados com solução salina (Se/SL) $(p<0,05)$. Entretanto, nos ratos do grupo sham não observamos diferença entre os animais tratados e não tratados com sinvastatina ( $p>0,05)$. Comparando os dados das citocinas dos ratos do grupo sham nas tabelas 1 e 2 , os valores mostram-se significativamente menores $(p<0,05)$ nos não diabéticos (Tabela 1) do que nos diabéticos (Tabela 2).

\section{Dosagens bioquímicas}

Os ratos diabéticos com sepse e tratados com sinvastatina (Se-S) tiveram níveis de PCT mais baixos $(3,4 \pm 1,8 \mathrm{ng} / \mathrm{mL})$ do que os tratados com solução salina $(6,1 \pm 2,2 \mathrm{ng} / \mathrm{mL})$ e a diferença foi significante $(\mathrm{p}=0,03)$. A mesma interpretação estatística foi repetida no grupo de

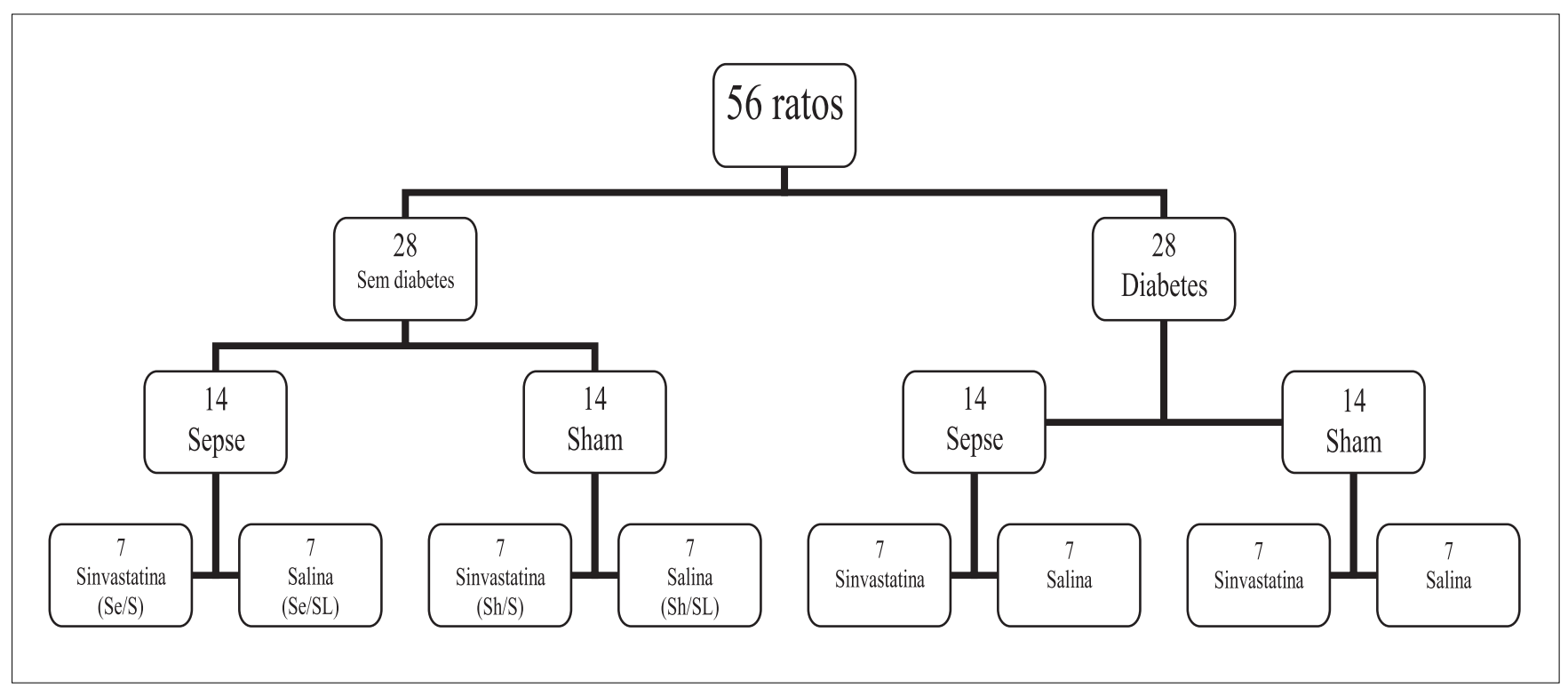

Figura 1 - Delineamento experimental: Ratos diabéticos e não diabéticos foram alocados em grupos: sepse (14 cada) e sham (14 cada). Os ratos com sepse foram tratados com sinvastatina (Se/S) e com solução salina (Se/SL). Os ratos sham foram também tratados com sinvastatina (Sh/S) e solução salina (Sh/SL). 
Tabela 1 - Leucometria, percentual de neutrófilos e dosagens de citocinas em ratos não diabéticos.

\begin{tabular}{lccccc}
\hline Grupos & Leuc/ $\mu \mathrm{L})$ & Neutrófilos $(\%)$ & TNF $\boldsymbol{\alpha}(\mathrm{pg} / \mathrm{mL})$ & $\mathrm{IL}-1 \boldsymbol{\beta}(\mathrm{pg} / \mathrm{mL})$ & $\mathrm{IL}-6(\mathrm{pg} / \mathrm{mL})$ \\
\hline Se/SL & $9,46 \pm 1,26^{\mathrm{ab}}$ & $76,37 \pm 6,5^{\mathrm{abc}}$ & $758,5 \pm 32^{\mathrm{a}}$ & $176,9 \pm 26^{\mathrm{a}}$ & $133,6 \pm 20^{\mathrm{a}}$ \\
Se/S & $6,72 \pm 0,39^{\mathrm{ab}}$ & $56,50 \pm 7,08^{\mathrm{a}}$ & $344,8 \pm 21^{\mathrm{a}}$ & $43,3 \pm 11^{\mathrm{a}}$ & $38,4 \pm 6^{\mathrm{a}}$ \\
Sh/SL & $4,68 \pm 0,56^{\mathrm{a}}$ & $57,17 \pm 6,60^{\mathrm{b}}$ & $21,3 \pm 3$ & $25,1 \pm 5$ & $22,8 \pm 2,6$ \\
Sh/S & $4,32 \pm 0,53^{\mathrm{b}}$ & $57,10 \pm 8,52^{\mathrm{c}}$ & $20,7 \pm 2^{\mathrm{a}}$ & $21,3 \pm 2^{\mathrm{a}}$ & $20,1 \pm 3^{\mathrm{a}}$ \\
\hline
\end{tabular}

Se-SL, Sepse-salina; Se-S, Sepse sinvastatina; Sh-SL,sham salina; Sh-S, Sham sinvastatina. Valores seguidos da mesma letra na mesma coluna diferem de modo significante $(p<0,05$, Teste de Tukey).

Tabela 2 - Valores de contagem de leucócitos, \% de neutrófilos e dosagem de citocinas de ratos diabéticos.

\begin{tabular}{lccccc}
\hline Grupos & Leuc/ $\mu \mathrm{L})$ & Neutrófilos $(\%)$ & TNF $\boldsymbol{\alpha}(\mathrm{pg} / \mathrm{mL})$ & $\mathrm{IL}-1 \boldsymbol{\beta}(\mathrm{pg} / \mathrm{mL})$ & $\mathrm{IL}-6(\mathrm{pg} / \mathrm{mL})$ \\
\hline Se/SL & $12,36 \pm 0,4 \mathrm{ab}$ & $84,32 \pm 7,5 \mathrm{abc}$ & $884,2 \pm 27^{\mathrm{a}}$ & $433,6 \pm 16^{\mathrm{a}}$ & $221,5 \pm 14^{\mathrm{a}}$ \\
Se/S & $7,28 \pm 0,5 \mathrm{ab}$ & $66,40 \pm 6,1 \mathrm{a}$ & $531,4 \pm 29^{\mathrm{a}}$ & $76,1 \pm 18^{\mathrm{a}}$ & $118,4 \pm 13^{\mathrm{a}}$ \\
Sh/SL & $4,9 \pm 0,3 \mathrm{a}$ & $46,14 \pm 5,2 \mathrm{~b}$ & $97,2 \pm 11$ & $34,1 \pm 6$ & $22,8 \pm 7$ \\
Sh/S & $5,34 \pm 0,5 \mathrm{~b}$ & $49,15 \pm 5,1 \mathrm{c}$ & $73,7 \pm 12^{\mathrm{a}}$ & $27,6 \pm 5^{\mathrm{a}}$ & $25,4 \pm 5^{\mathrm{a}}$ \\
\hline
\end{tabular}

Se-SL, Sepse-salina; Se-S, Sepse-sinvastatina; Sh-SL,sham-saline; Sh-S, Sham-sinvastatina. Valores seguidos da mesma letra na mesma coluna diferem de modo significante $(p<0,05$, Teste de Tukey).

animais sépticos não diabéticos. Nós não observamos diferenças significantes nos níveis de PCT comparando os animais diabéticos e não diabéticos do grupo sham tratados com solução salina ou com sinvastatina. Os níveis de PCT mostraram-se significativamente reduzidos nos animais são sépticos (sham) comparados com os animais com sepse, como pode ser observado na tabela 3. Os níveis de PCR (Tabela 3) seguiram a mesma interpretação da PCT, ou seja, os ratos diabéticos e não diabéticos com sepse, tratados com sinvastatina, tiveram níveis de PCR significativamente menores do que nos animais tratados com solução salina $(p<0,05)$.

\section{DISCUSSÃO}

Apesar dos recentes avanços na antibioticoterapia e nas medidas de suporte, a mortalidade dos pacientes com sepse continua nos níveis de 27 a $50 \%{ }^{17}$. Entre outros fatores, o prognóstico desfavorável de pacientes com sepse é causado pelo diagnóstico tardio e por doenças intercorrentes como diabetes mellitus ${ }^{18}$, cirrose hepática e imunodepressão. Pacientes diabéticos estão em risco permanente de colonização por Staphylococcus aureus, resultando em alto risco de infecção de pele e tecidos moles, e sepse por $S$. aureus ${ }^{19}$. Além disso, o diabetes constitui um fator de risco para bacteremia devida a Enterobacteriaceae ${ }^{20}$, e abscesso hepático piogênico ${ }^{21}$.

A fase aguda da resposta à sepse, que inclui uma grande variedade de mediadores tais como PCR, IL-6, TNF$\alpha$, e IL-1 $\beta$, pode ser influenciada pelas estatinas. No presente estudo, os níveis de TNF- $\alpha$, IL-1 $\beta$ e IL- 6 aumentaram de modo significante após a indução da sepse e diabetes. Entretanto nos ratos tratados com sinvastatina os níveis séricos de citocinas mostraram-se significativamente mais baixos em comparação com os animais do grupo sham, o que fala a favor de evidente ação antiinflamatória da sinvastatina. Nossos resultados estão de acordo com dados de outros estudos 22,23 . Camundongos tratados com estatina antes da injeção de lipopolissacarídeos expressaram níveis séricos reduzidos de TNF- $\alpha$ e IL- $1 \beta$ após duas horas, e essas alterações repercutiram em aumento na sobrevida dos animais tratados ${ }^{24}$. A propósito, estes resultados coincidem com os dados do presente estudo e confirmam dados de outro

Tabela 3 - Valores de procalcitonina e proteína C reativa nos animais diabéticos e não diabéticos.

\begin{tabular}{|c|c|c|c|c|}
\hline \multirow[t]{2}{*}{ Grupos } & \multicolumn{2}{|c|}{ Diabetes } & \multicolumn{2}{|c|}{ Sem diabetes } \\
\hline & PCT (ng/mL) & PCR (mg/L) & PCT (ng/mL) & PCR (mg/L) \\
\hline $\mathrm{Se} / \mathrm{SL}$ & $6,1 \pm 2,2^{a . b}$ & $22,5 \pm 4,3^{c}$ & $4,3 \pm 0,5^{b}$ & $18,6 \pm 3,7^{d}$ \\
\hline $\mathrm{Se} / \mathrm{S}$ & $3,4 \pm 1,8^{a}$ & $14,7 \pm 4,1^{c}$ & $3,2 \pm 0,4^{b}$ & $10,9 \pm 4,9 d$ \\
\hline $\mathrm{Sh} / \mathrm{SL}$ & $0,7 \pm 0,2^{b}$ & $2,2 \pm 0,4^{c}$ & $1,2 \pm 0,09 b$ & $0,3 \pm 0,07^{d}$ \\
\hline $\mathrm{Sh} / \mathrm{S}$ & $0,4 \pm 0,05^{a}$ & $2,4 \pm 0,3$ & $0,9 \pm 0,02$ & $0,6 \pm 0,12$ \\
\hline
\end{tabular}

PCR, Proteína C reativa; PCT, procalcitonina; Se-SL, Sepse-salina; Se-S, Sepse-sinvastatina; Sh-SL,sham-salina; Sh-S, Sham-sinvastatina. Valores seguidos da mesma letra, na mesma coluna, diferem de modo significante ( $p<0,05$, Teste de Tukey). 
estudo do nosso laboratório. Ratos não diabéticos tiveram boa sobrevida, redução na leucometria e em citocinas próinflamatórias sob efeito da sinvatatina ${ }^{25}$. No presente estudo, um nível de sobrevida favorável foi observado em animais diabéticos e não diabéticos com sepse abdominal tratados com sinvastatina. No delineamento experimental deste estudo usamos tratamento preventivo da sepse com sinvastatina. Os ratos foram tratados com duas doses por via oral com microemulsão de sinvastatina nos momentos 18 horas e três horas antes da indução da sepse, seguindo modelo usado em outro estudo ${ }^{26}$. A microemulsão foi preparada em um de nossos laboratórios (Laboratório de Sistemas Dispersos-UFRN). Alguns modelos de sepse animal têm dado suporte à suposição de que as estatinas podem ser eficazes na prevenção da sepse $\mathrm{e}^{26,27}$, mas pouco se sabia sobre o uso de estatinas na sepse de diabéticos.

Modelo experimental de camundongos, com sepse tratados com sinvastatina, comprovou que eles tiveram sobrevida quatro vezes mais longa do que controles, enquanto as funções hemodinâmica e cardíaca mantiveram-se completamente preservadas ${ }^{26}$. Em outro estudo ficou comprovado que o pré-tratamento com sinvastatina foi suficiente para prevenir infecção e disfunção coronariana em suínos, e esses benefícios foram independentes dos efeitos hipolipemiantes do fármaco ${ }^{27}$. Em nosso laboratório estudamos o efeito tópico da sinvastatina em feridas infectadas de ratos. Os níveis teciduais das citocinas mostraram-se reduzidos, o crescimento bacteriano foi inibido nas feridas do grupo experimental e a cicatrização foi estimulada. Esses achados corroboram a idéia de que a sinvastatina tem um provável efeito antibacteriano ${ }^{28}$.

Em humanos, PCR e PCT circulantes têm sido associadas à infecção e sepse ${ }^{6,7}$. Em pacientes com diabetes tipo 2 foram encontrados níveis séricos elevados de PCR, cujos resultados também foram correlacionados com significante preditor de mortalidade cardiovascular em um estudo prospectivo de pacientes com diabetes tipo $2^{29}$. Alguns autores descreveram uma prevalência significante de altas concentrações de PCR em pacientes $\operatorname{críticos}^{30}$. Neste estudo empregamos pré-tratamento com sinvastatina, que contribuiu para a diminuição dos níveis séricos de $P C R$ em ratos sépticos diabéticos e não diabéticos, significando que o fármaco exerceu um efeito preventivo na expressão dos biomarcadores da sepse como PCR e citocinas.

A procalcitonina é um marcador para a identificação de infecção sistêmica, que não reage na presença de inflamação não infecciosa ou em infecção localizada? PCT é um pró-hormônio marcador da sepse, que representa o precursor da calcitonina. Em estudos de diagnóstico e prognóstico, a PCT respondeu bem a estratégias de tratamento da sepse e funcionou como um bom marcador para monitorar os efeitos do tratamento ${ }^{7}$. De fato, neste estudo nós observamos que a PCT apresentou-se com níveis séricos elevados em ratos diabéticos com e sem sepse e que, o pré-tratamento com sinvastatina resultou na diminuição dos níveis de PCT. Estes resultados contribuíram para validar, pelo menos em parte, a eficácia da sinvastatina na sepse abdominal.

Este estudo demonstrou que a sinvastatina tem efeitos antiinflamatórios e constitui uma possível estratégia terapêutica para o tratamento da sepse abdominal em diabéticos. Os dados disponíveis podem ter possíveis implicações clínicas em futuras investigações.

\section{Agradecimentos}

Agradecemos ao CNPq, Ministério da Ciência e Tecnologia, Brasil, pela concessão de recursos para a realização deste estudo (Protocolo n 470862/07).

\section{A B S T R A C T}

Objective: Infection and sepsis are major causes of morbidity and mortality after surgery of diabetic patients. Statins have been shown to exhibit anti-inflammatory and immunomodulatory (pleiotropic) effects, independent of lipid lowering. This study aimed to observe whether the pretreatment with simvastatin in a cecal ligation and perforation model of sepsis is beneficial in diabetic rats. Methods: Fifty six Wistar rats were randomly assigned to non-diabetic group $(n=28)$, and streptozotocin-induced diabetic group $(n=28)$. Abdominal sepsis was induced in 14 diabetic and in 14 non diabetic rats and the other 28 rats were allocated on sham group. Sepsis rats and sham rats (each with 7 animals) were treated with oral simvastatin (20 mg kg-1 day-1) or normal saline solution $0.9 \%$. Peripheral blood TNF $\alpha, I L-1 \beta, I L-6, C$-reactive protein, procalcitonin, leukocytes and neutrophils were tested in all the animals. Statistical analysis was done by ANOVA and Tukey test, with $p<0.05$. Results: Simvastatin reduced mortality in diabetic rats. Peripheral blood TNF $\alpha, I L-1 \beta, I L-6, C$-reactive protein, procalcitonin, leukocytes and neutrophils were lower in diabetic and non diabetics septic rats treated with simvastatin, than after saline treatment. Conclusion: Simvastatin showed anti-inflammatory effect, which could play some protection against the progress of sepsis in diabetic rats.

Key words: Simvastatin. Sepsis. Diabetes. Streptozotocin. Rats.

\section{REFERENCIAS}

1. Poschl JM, Leray C, Ruef P, Cazenave JP, Linderkamp O. Endotoxin binding to erythrocyte membrane and erythrocyte deformability in human sepsis and in vitro. Crit Care Med. 2003;31(3):924-8.
2. Moutzouri A, Skoutelis A, Gogos C, Missirlis Y, Athanassiou G. Red blood cell deformability in patients with sepsis: a marker for prognosis and monitoring of severity. Clin Hemorheol Microcirc. 2007;36(4):291-9.

3. Ince $C$, Sinaasappel M. Microcirculatory oxygenation and shunting in sepsis and shock. Crit Care Med. 1999;27(7):1369-77. 
4. Astiz ME, DeGent GE, Lin RY, Rackow EC. Microvascular function and rheological changes in hyperdynamic sepsis. Crit Care Med. 1995:23(2):265-71.

5. Casey LC, Balk RA, Bone RC. Plasma cytokine and endotoxin levels correlate with survival in patients with the sepsis syndrome. Ann Intern Med. 1993;119(8):771-8.

6. Povoa $P$, Coelho L, Almeida E, Fernandes A, Mealha R, Moreira P, Sabino $\mathrm{H}$. C-reactive protein as a marker of infection in critically ill patients. Clin Microbiol Infect. 2005;11(2):101-8.

7. Christ-Crain M, Jaccard-Stolz D, Bingisser R, Gencay MM, Huber PR, Tamm M, Müller B. Effect of procalcitonin-guided treatment on antibiotic use and outcome in lower respiratory tract infections: cluster-randomised, single-blinded intervention trial. Lancet. 2004;363(9409):600-7.

8. Müller LM, Gorter KJ, Hak E, Goudzwaard WL, Schellevis FG, Hoepelman Al, et al. Increased risk of common infections in patients with type 1 and type 2 diabetes mellitus. Clin Infect Dis. 2005;41(3):281-8. Epub 2005 Jun 16.

9. Bertoni $A G$, Saydah S, Brancati FL. Diabetes and the risk of infectionrelated mortality in the U.S. Diabetes Care. 2001;24(6):1044-9.

10. Alba-Loureiro TC, Munhoz CD, Martins JO, Cerchiaro GA, Scavone C, Curi R, et al. Neutrophil function and metabolism in individuals with diabetes mellitus. Braz J Med Biol Res. 2007:40(8):1037-44.

11. Ross R. Atherosclerosis-an inflammatory disease. N Engl J Med. 1999; 340(2):115-26.

12. Liao JK. Beyond lipid lowering: the role of statins in vascular protection. Int J Cardiol. 2002; 86(1): 5-18.

13. Jacobson JR, Barnard JW, Grigoryev DN, Ma SF, Tuder RM, Garcia JG. Simvastatin attenuates vascular leak and inflammation in murine inflammatory lung injury. Am J Physiol Lung Cell Mol Physiol. 2005; 288(6):1026-32. Epub 2005 Jan 21

14. Steiner S, Speidl WS, Pleiner J, Seidinger D, Zorn G, Kaun C, et al. Simvastatin blunts endotoxin induced tissue factor in vivo. Circulation. 2005; 111(14): 1841-46.

15. Dichtl W, Dulak J, Frick M, Alber HF, Schwarzacher SP, Ares MP, et al. HMG-CoA reductase inhibitors regulate inflammatory transcription factors in human endothelial and vascular smooth muscle cells. Arterioscler Thromb Vasc Biol 2003;23(1):58-63.

16. Durant R, Klouche K, Delbosc S, Morena M, Amigues L, Beraud JJ, et al. Superoxide anion overproduction in sepsis: effects of vitamin e and simvastatin. Shock. 2004;22(1):34-9.

17. Vincent JL, Sakr Y, Sprung CL, Ranieri VM, Reinhart K, Gerlach H, et al. Sepsis in European intensive care units: results of the SOAP study. Crit Care Med. 2006;34(4):344-53.

18. Stoeckle M, Kaech C, Trampuz A, Zimmerli W. The role of diabetes mellitus in patients with bloodstream infections. Swiss Med Wkly. 2008;138(35-36):512-9.

19. Kaech C, Elzi L, Sendi P, Frei R, Laifer G, Bassetti S, et al. Course and outcome of Staphylococcus aureus bacteraemia: a retrospective analysis of 308 episodes in a Swiss tertiary-care centre. Clin Microbiol Infect. 2006;12(4):345-52.

20. Thomsen RW, Hundborg HH, Lervang HH, Johnsen SP, Schonheyder $\mathrm{HC}$, Sorensen HT. Diabetes mellitus as a risk and prognostic factor for community-acquired bacteremia due to enterobacteria: a 10- year, population-based study among adults. Clin Infect Dis 2005;40(4):628-31. Epub 2005 Jan 26.

21. Thomsen RW, Jepsen $P$, Sorensen HT. Diabetes mellitus and pyogenic liver abscess: risk and prognosis. Clin Infect Dis. 2007;44(9):1194-201. Epub 2007 Mar 28.

22. Pleiner J, Schaller G, Mittermayer F, Zorn S, Marsik C, Polterauer $S$, et al. Simvastatin prevents vascular hyporeactivity during inflammation. Circulation. 2004;110(21):3349-54. Epub 2004 Nov 1

23. Rezaie-Majd A, Maca $T$, Bucek RA, Valent $P$, Müller MR, Husslein $P$, et al. Simvastatin reduces expression of cytokines interleukin-6, interleukin-8, and monocyte chemoattractant protein-1 in circulating monocytes from hypercholesterolemic patients. Arterioscler Thromb Vasc Biol. 2002;22(7):1194-9.

24. Ando H, Takamura T, Ota T, Nagai Y, Kobayashi K. Cerivastatin improves survival of mice with lipopolysaccharide-induced sepsis. J Pharmacol Exp Ther. 2000;294(3):1043-6.

25. Souza Neto JL, Araújo Filho I, Rego AC, Dominici VA, Azevedo IM, Medeiros AC. Effects of simvastatin in abdominal sepsis in rats. Acta Cir Bras. 2006;21 (Suppl 4):8-12

26. Merx MW, Liehn EA, Janssens U, Lütticken R, Schrader J, Hanrath $P$, et al. HMG-CoA reductase inhibitor simvastatin profoundly improves survival in a murine model of sepsis. Circulation. 2004; 109(21): 2560-5. Epub 2004 May 3

27. Liuba P, Pesonen E, Forslid A, Paakkari I, Kornerup-Hansen A, Kovanen $P$, et al. Protective effects of simvastatin on coronary artery function in swine with acute infection. Atherosclerosis. 2006;186(2):331-6. Epub 2005 Oct 11.

28. Rego AC, Araújo Filho I, Damasceno BP, Egito ES, Silveira IA, Medeiros AC. Simvastatin improves the healing of infected skin wounds of rats. Acta Cir Bras. 2007;(Suppl 1):57-63.

29. Soinio M, Marniemi J, Laakso M, Lehto S, Rönnemaa T. High sensitivity C-reactive protein and coronary heart disease mortality in patients with type 2 diabetes: a 7-year follow-up study. Diabetes Care. 2006;29(2):329-33. Lobo SM, Lobo FR, Bota DP, LopesFerreira F, Soliman HM, Vincent JL. C-reactive protein levels correlate with mortality and organ failure in critically ill patients. Chest. 2003;123(3):2043-9

\section{Recebido em 12/01/2009}

Aceito para publicação em 12/03/2009

Conflito de interesse: nenhum

Fonte de financiamento: CNPq (Protocolo 470862/07)

\section{Como citar esse artigo:}

Araújo-Filho I, Jacome DT, Rego ACM, Azevedo IM, Egito EST, Medeiros AC. Efeito da sinvastatina na sepse abdominal de ratos diabéticos. Rev Col Bras Cir. [periódico na Internet] 2010; 37(1). Disponível em URL: http://www.scielo.br/rcbc

\section{Endereço para correspondência:}

Aldo C. Medeiros

aldo@ufrnet.br 